\title{
Coupling Charge Reduction Mass Spectrometry to Liquid Chromatography for Complex Mixture Analysis
}

John R. Stutzman, ${ }^{1}$ Matthew C. Crowe, ${ }^{2}$ James N. Alexander IV, ${ }^{2}$ Bruce M. Bell, ${ }^{1}$ Melissa N. Dunkle ${ }^{3}$

\author{
${ }^{1}$ Analytical Sciences \\ The Dow Chemical Company \\ Midland, MI, USA, 48667 \\ ${ }^{2}$ Analytical Sciences \\ The Dow Chemical Company \\ Collegeville, PA, USA, 19426 \\ ${ }^{3}$ Analytical Sciences \\ The Dow Chemical Company \\ Terneuzen, NL
}

Table of Contents

Page S-2: Figure SI-1, MALDI-TOF analysis of PEG5000

Page S-3: Figure SI-2, PEG2500 LC/MS and LC/CR/MS analysis

Page S-4: Figure SI-3, Triblock polyol LC/MS and LC/CR/MS analysis 


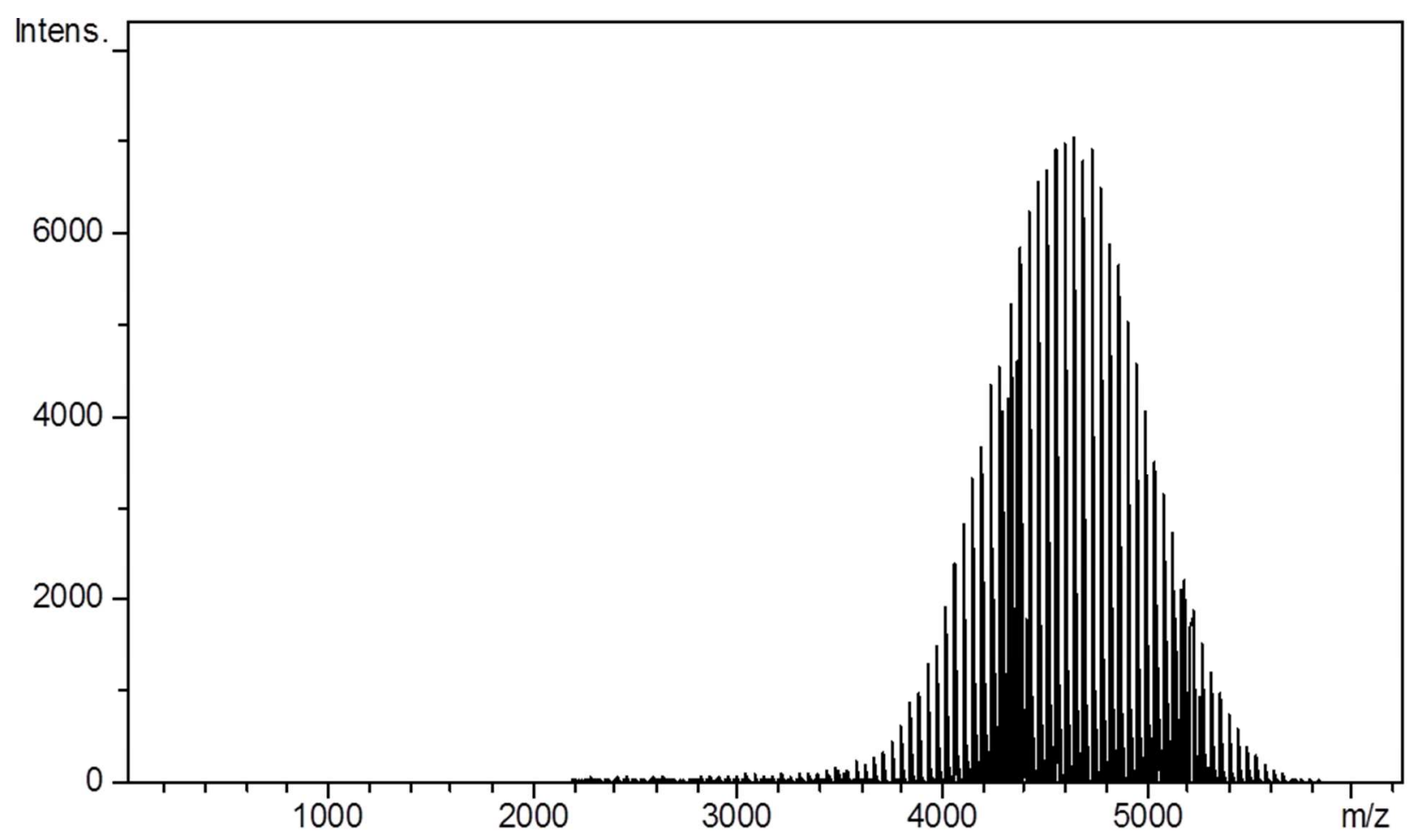

SI-1. MALDI-TOF analysis of PEG5000. 

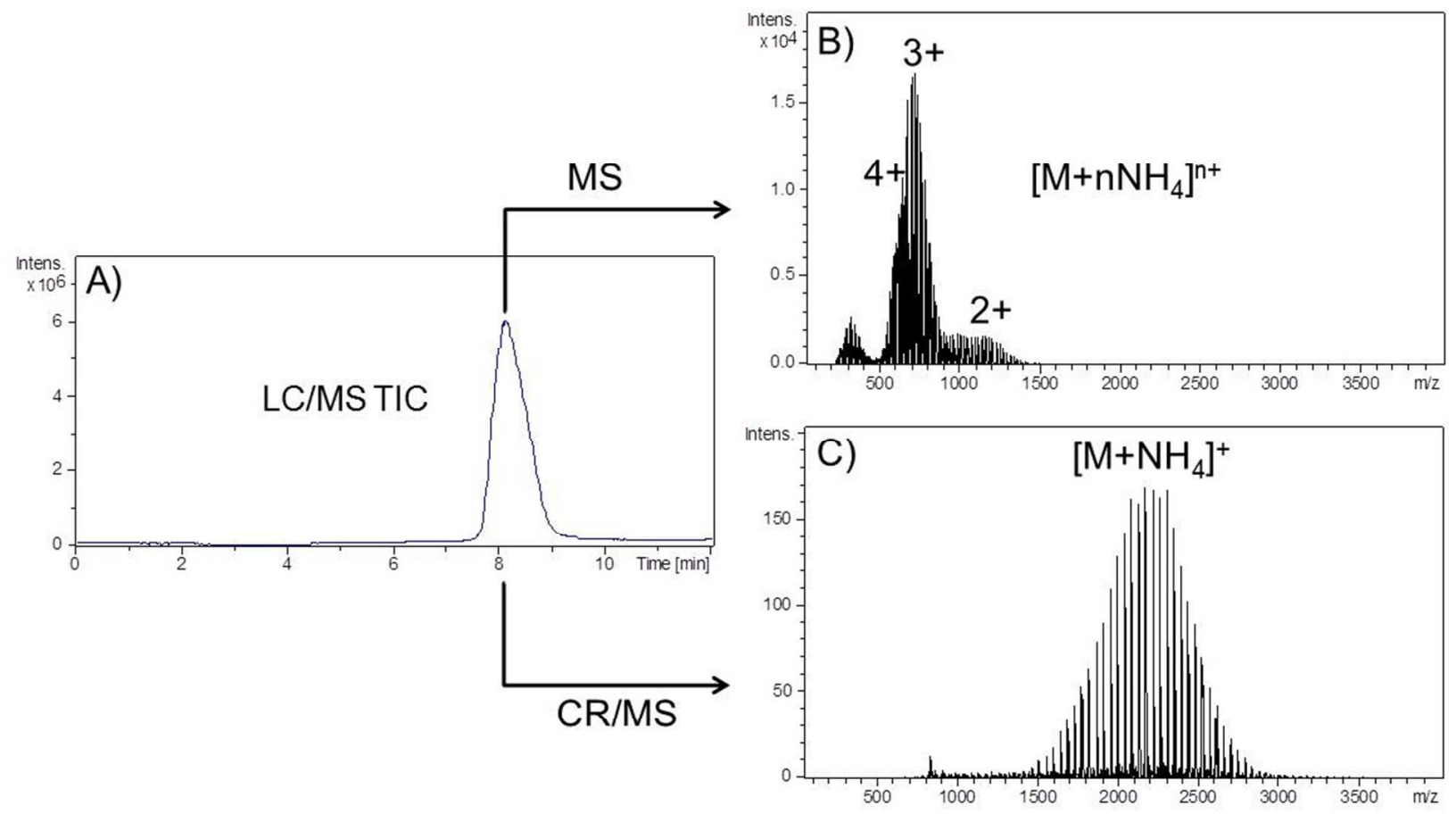

SI-2. A) Total ion chromatogram for LC/MS of PEG2500, B) Summed mass spectrum from LC/MS analysis of PEG2500, C) Summed mass spectrum from LC/CR/MS analysis of PEG2500 


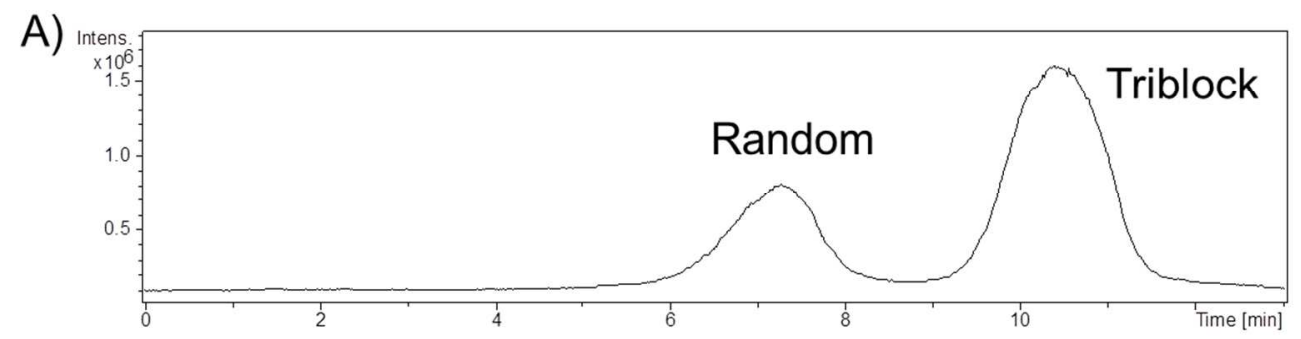

B)

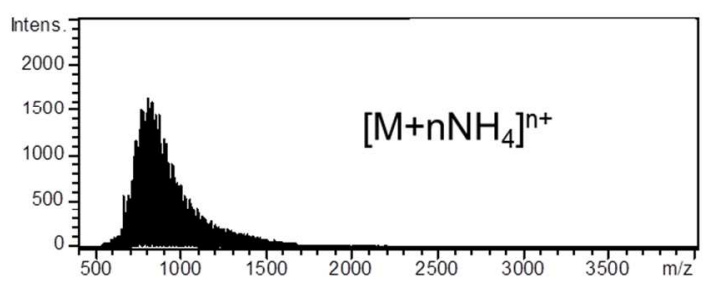

D)

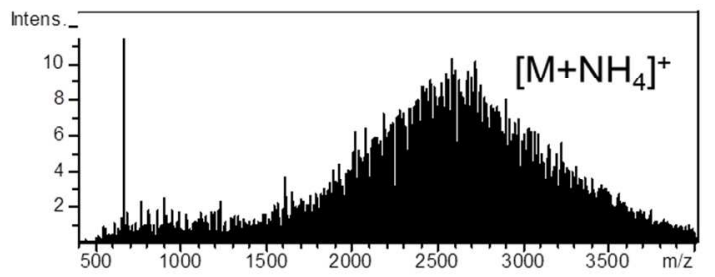

C)

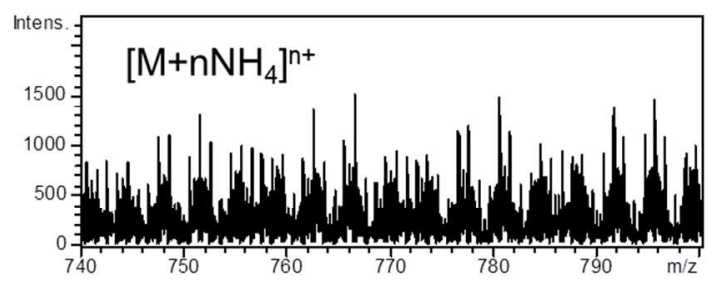

E)

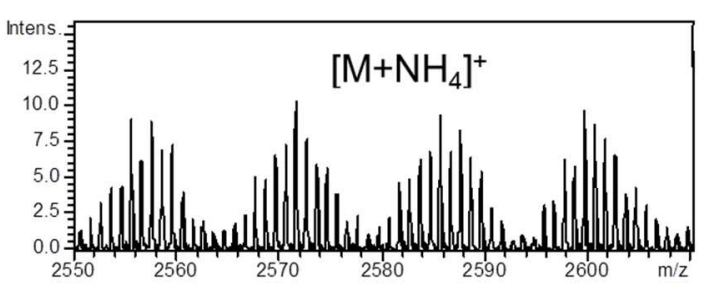

SI-3. A) LC/MS TIC of 1:1 mixture of random:triblock EO/PO polyol. Summed mass spectrum of B) LC/MS results for the triblock polyol, C) LC/MS inset from $m / z$ 740-800, D) LC/CR/MS for the triblock polyol, E) LC/CR/MS inset from $\mathrm{m} / \mathrm{z} 2550-2610$ 